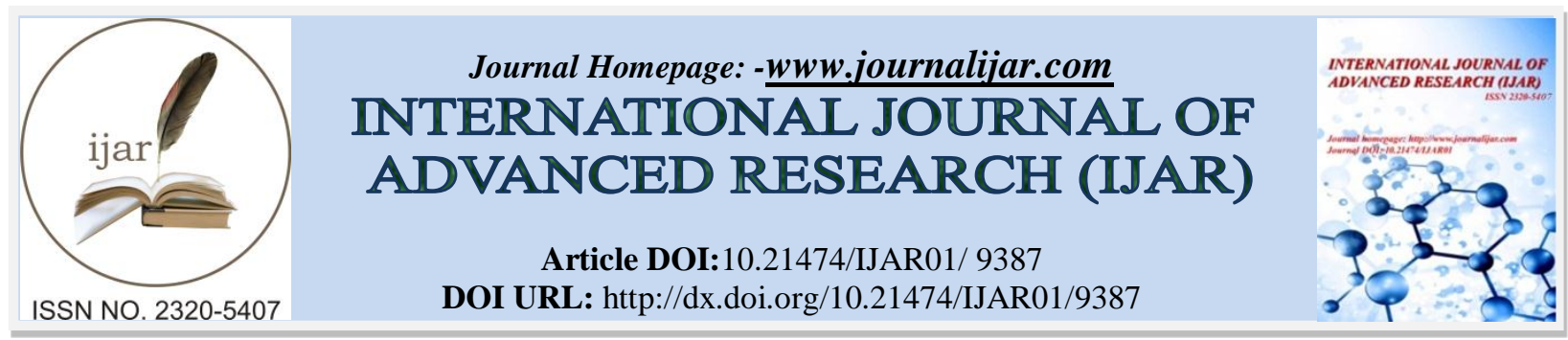

RESEARCH ARTICLE

\title{
NARRATIVE TRANSFORMATIONS, AS ONE OF THE MAIN INSTRUMENT FOR MODELING NARRATIVE DISCOURSE.
}

\begin{abstract}
Yusupova Guzal Rashitovna.
Ph.D., teacher of Samarkand State Institute of Foreign languages, Uzbekistan, Samarkand city, Bagizaganskaya street, house 1.
\end{abstract}

\section{Manuscript Info}

Manuscript History

Received: 15 May 2019

Final Accepted: 17 June 2019

Published: July 2019

Key words:-

narrative transformation, cognitive modeling, narrative discourse, "stream of consciousness", inferention, transposition of characters, temporal transposition.

\begin{abstract}
The manuscript presents an investigation of the peculiarities of modeling narrative transformations in the discourse of "stream of consciousness" and their representation in the fiction on the basis of W. Faulkner's novel "The sound and the Fury". Not less important in the work the main means and devices which perform these transformations and their motivation. Much attention is given to the communicative significance of all narrative transformations simulated by W. Faulkner in the text. The author of the manuscript has researched launched inferential mechanisms of further connotations (added meaning) "construction" on the conditions predefined by the text. Researcher also considered cognitive-communicative functions of "stream of consciousness" discourse of W. Faulkner's novel "The sound and the Fury" from the perspective of the literary text perception. The main focus of the research was on temporal transposition and transposition of characters.
\end{abstract}

Copy Right, IJAR, 2019,. All rights reserved.

\section{Introduction:-}

Not by accident, K. Malevich's Black Square becomes the symbol of a new era in the 20th century - the era of "the tragedy of aesthetics". In art a peculiar virtual world is forming which exists according to the laws generated by human consciousness. Encoding the meaning and arbitrariness of the image lead to the destruction of traditional understanding of communication, which transfers into a game, where everyone determine his rules.

The novel "The Sound and the Fury" by Nobel Prize winner William Faulkner represents an overbold artistic experiment. Extraordinary and at first sight illogical models of narrative constructions, implemented in the technique of author's writing, do not represent an end in itself, they simply in the best way corresponds to appropriate aesthetic aim that author has set for himself. Many researchers note the following regularity in literary text modeling: "Literary text viewed from the standpoint of creative consciousness is analyzed as the process of text creation, where, on the one hand, function the tendency of automatism, the desire for regularity inherent in common speech and on the other hand intentional actualization of potential language possibilities, that is the creation of neologisms at different language levels. "(Koltsova, 2007). All that is connected with the creation of neologisms is directly related to the novel "The Sound and the Fury" by William Faulkner.

Corresponding Author:-Yusupova Guzal Rashitovna.

Address:-Ph.D., teacher of Samarkand State Institute of Foreign languages, Uzbekistan, Samarkand 
First of all, it should be pointed out that the novels of W. Faulkner attracted and continue to attract the attention of many researchers with their formal and structural peculiarities of text organization. There is a huge number of models by which literary narrative discourse can be encoded, however, the way of encoding always depends on the author himself and his main idea. In her article E. A. Belousova notes the following: "At the moment of literary text interpretation there are launched inferential mechanisms of further connotations ( added meaning) "construction" on the conditions predefined by the text. (Belousova, 2012). Inferention is interpreted as " a cognitive operation of human thinking, in the course of which, based on the information directly contained in the text, reader goes beyond the given text and gets new information" (Dedova, 2001). By activating the processes of inferention, the reader can analyze not only vivid information but also the information, which in large numbers is contained in each text implicitly.

W. Faulkner can more be called an experimenter, rather than the creator in the literary field of the novel about the American South. Researchers (N. I. Matveeva (2003), N. A. Anastasiev (1976), T. M. Towner (2008), D. Fowler and Ann J. Abadie (2008)) note contradictory narrative experiments that characterize the novel "The Sound and the Fury". Analyzed novel by W. Faulkner is still interesting, as a prime example of a non-traditional narrative organization. In the article "Cognitive modeling of mental literary space (from the author to the reader)" K.A. Andreeva rightly notes the following: "The most interesting for the researcher are the cases when the development of events in the work of art deliberately moves along a parabolic trajectory that violates canonical narrative series. Most often this happens in modern authors in the literature of postmodernism "(Andreeva, 2008).

In our opinion, exactly this author is W. Faulkner, who creates a "mosaic" artistic space, realized through his special narrative code.

Narrative transformations are immediate constituents of literary text modeling. In it's turn narrative transformations are certain narrative devices, which directly depend not only on the genre, author's style and etc., they (narrative devices) also subordinate to the author's central idea. Narrative transformations appear as a result of author's rethinking of the main idea of the work, at the root of which, as a rule may be certain situation or story.

V. Schmidt points out the following: In the models of narrative constitution a narrative work is viewed as the result of a number of transformations. In these models, the work is decomposed into separate levels, stages of its constitution, and certain narrative devices are attributed to the transformations "(Schmid, 2003)

Analyzing peculiarities of narrative transformation and the problem of narrative constitution within the framework of the article it is necessary to distinguish such concepts as "story" and "discourse". There are a huge number of definitions for these concepts, but, to our view point, the most productive is the definition of Ts. Todorov, who argued that "... literary work contains two aspects: it simultaneously is both story and discourse. It is history in the sense that it evokes the image of a certain reality ... But the work is at the same time a discourse ... At this level, the undescribed events are not taken into account, but the way the narrator introduces us to them, " (Todorov, 1966).

Again let's make clear: story is the what in a narrative, discourse is the how. Consequently, if we are talking about "stream of consciousness" prose, it will be appropriate to use the term "discourse" because it contains the "story" in a transformed form.

It is important how the author organizes transformation of "the story" and how materialization of this story happen in signified text.

As a result of the fact that 3 chapters of 4 of analyzed novel "The Sound and the Fury" by William Faulkner represent "stream of consciousness" discourses that is why the author is not and can not be space and time guideline. As some kind of "compass" can be narrative of each character in the text. Therefore revealing communicative and guiding functions of discourses of the brothers heroes the story of the Compson family may be reconstructed to the extent that it was conceived by author.

Complex model of temporal correlations which author creates intentionally draws attention in the aspect of our study. The specificity of narration is in temporality so it is a definite way of expounded content configuration in 
time. At the same time key questions become correlation of different types of temporal configurations-single events, repeated events, conditions, universals, delimitation of time stream according to the ordered logic of moving events and another interpretation variants of time in narrative.

Consequently time is a substantial modeling modus in William Faulkner's novel «The sound and the Fury». At the same time the following notions should be distinguished: the time of the world and linguistic time. To our point of view the most accurate distinction of these notions is given by E. Farino, who states the following: "The time of the world can be transferred to the object of utterance and can be accessible to the character who exists in this world while linguistic time comes from the narrator (the speaker) and can create some kind of time perspectives ( view points) to narrative world, that is to transform it, for example, into present and past, into future or former and so on." (Farino, 2004). In the studied novel by W. Faulkner linguistic time predominates, as narration of its three parts is made on behalf of different characters in "stream of consciousness" technique and only the last fourth is on behalf of author himself. In the latter case we deal with "the time of the world".

At the same time it should be emphasized, that special interest in the category of time is most typical for the last decades of the 21 st century. (Andrews, Squire, Tamoukou, Ricoeur, Genette, Andreeva, Paducheva, Turaeva, Zolotova and etc.) It reflects the features of this literature, which is characterized by processes of special interpretation of time, complex web of different temporal layers, intrusion into their sequence, irregularities in narration. (Ushnikova, 2010). It can be said, that all above-listed peculiarities of the category of time, as a category of narrative, W. Faulkner uses in his novel. The sense of confused time on macro and micro-text levels, abrupt transitions to different time layers ( in the context of each chapter and the whole novel), "intrusion" into their sequence, compositional "intrusion" (the chapters are arranged in a non- chronological sequence) are narrative devices, which author intertwines into the strands of the whole novel narrative.

"Importance of the category of time is manifested in the fact that it is temporal orientation of the work determines the character of linguistic means used by author in his work" (Turaeva, 1986). At that it is necessary to determine the difference between grammatical and artistic time. Z.Ya. Turaeva affirms the following: "Artistic and grammatical times are different forms of time. Both forms of time synthesize and, in their own way, refract properties of objective, perceptual and individual time" (Turaeva, 1986).

The study of cognitive-communicative functions of "stream of consciousness" discourse from the perspective of the artistic text perception is most productive when it is divided into narrative levels. For a more complete characteristics of a viewed question, V. Schmid's theory was studded where he puts forward the model of narrative constitution. This model corresponds to bivalent meanings of terms "fibula " (fabula) and "sujet" (syuzhet), or histoire и discours. V. Schmid views three-level models developed from the dichotomy of Russian formalists and French structuralists, as J. Genett, Sh. Rimmon-Kenan, M. Bal, H.A. Garcia Landa. In a consolidated manner, these models get a kind of the triad "event-story-image (text) of the story". V. Schmid himself proposed replacing a dichotomy, and the triad by the model in four levels: events, story, narration and presentation of narration. Developing V. Schmid's theory and projecting it onto the "stream of consciousness" discourse, or more precisely, on the example of the studied novel by W. Faulkner, should be emphasized the following regularity. The mechanism of text interpretation in our case is organized in the following sequence: presentation of narration-narration-events-story.

Presentation of narration is a narrative text that is accessible to empirical observation. The main way of presentation of narration is verbalization, that is, narrative transmission by means of language - not of cinema, ballet or music.

Narration is the result of a composition that organizes the elements of events in an artificial order (Schmid, 2003). In his novel, W. Faulkner deliberately organizes the configuration of events in a non-chronological order, which is a transposition of parts of the story that do not correspond to traditional narrative logic. As is well known, W. Faulkner's novel "The Sound and the Fury" is a work where a special technique of writing "stream of consciousness" is used, which focused on displaying the processes taking place in the character's mind. In the novel this technique is implemented through special organization of narrative structure, with various shifts in narrative plans (transpositions). Matveeva N.I. gives the following definition of the term "narrative transposition": "By narrative transposition we mean a clearly defined character, temporal, spatial or thematic shift of narrative plans from one to another." (Matveeva, 2003). All of above mentioned types of transpositions are found in W. Faulkner's novel "The Sound and the Fury", whose boundaries are marked not only through chapters. Note the level of "maximum" 
(conditionally designated by us) labeled at the level of chapters. (April 7, 1928; June 2, 1910; April 6, 1928; April 8, 1928). A "minimum" level can be considered a transposition even within one sentence. To substantiate Faulkner's non traditional narrative logic, it is necessary first of all to reveal basic characteristics of a traditional novel. Traditional novel is defined as follows: "Due to the fact that in literary work all phenomena are gathered in spatial, temporal and semantic whole of the completed event of life, in traditional forms of the novel, the narrative composition is formed by the sequential development of such an event." (Matveeva, 2003). All above mentioned is destroyed by narrative transpositions, deliberately created by Faulkner in this novel, by its "displacement" in time and space.

It is impossible to line up an event series of the novel without the chronological table of A. Dolinin, (Dolinin, 1985), which highlights the most significant episodes in the life of the Compson family:

1898- Death of grandmother

1910 (04.24) - Caddy's Wedding

1910 (2.06) - Quentin's Suicide

We selectively use only those events that, in our opinion, are centered in each chapter on the perception of characters. W. Faulkner focuses each of them through the perception of different intellectual, moral and social types.

In our view, temporary transposition dominates in the novel. It should be noted that W. Faulkner structures his novel, dividing it into four unequal parts, focused on the image of one day in the life of each character, where the indicator for each chapter is the specific date of the described event.

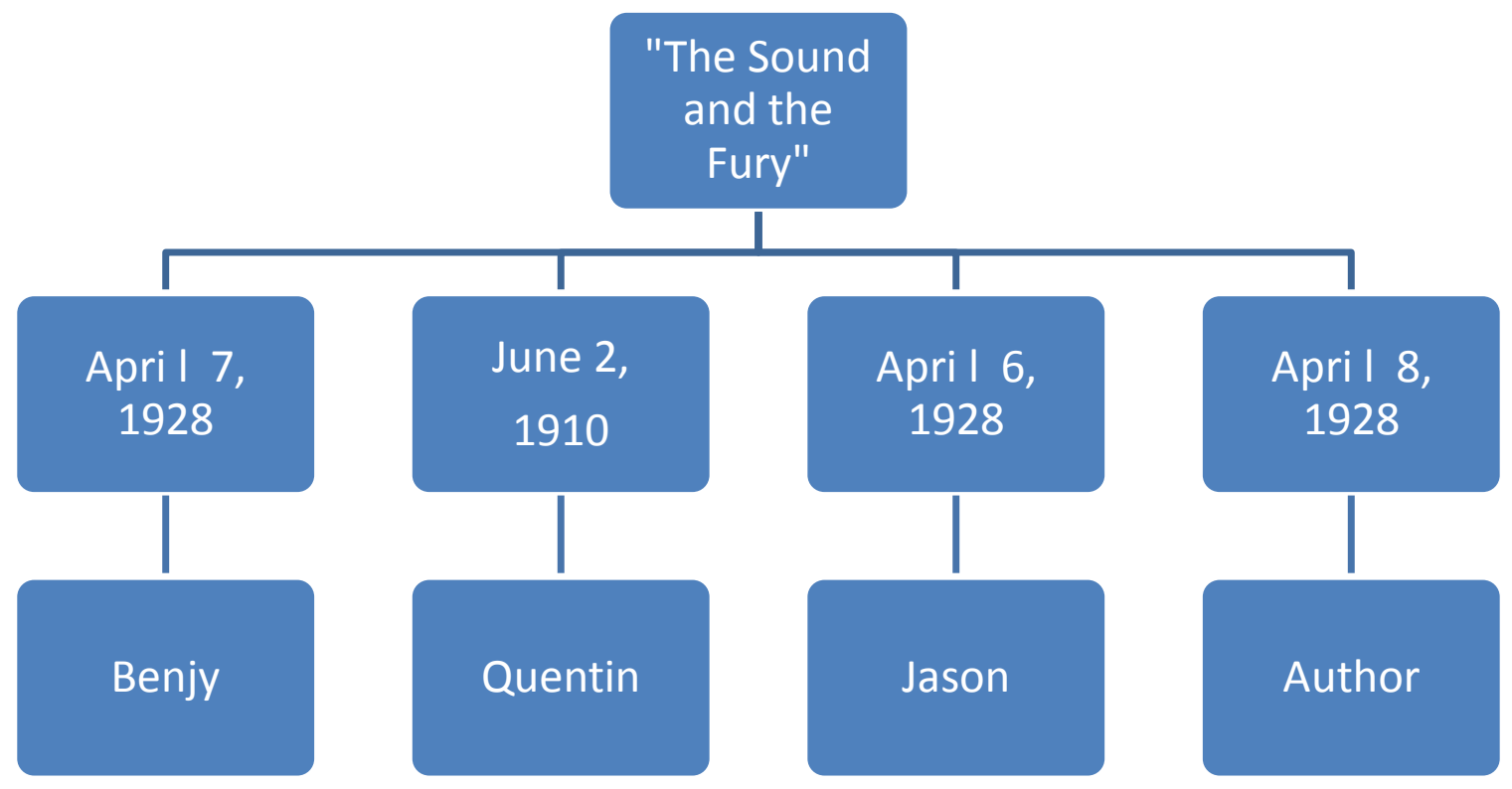

The importance of the time layer and the use of non-chronological temporal narrative transposition in structuring the novel chapters are strictly motivated by the author's literary intent. We believe that the mentioned tem porary transpositional structure in the construction of the novel chapters corresponds to the tragic, emotional perception and characterizes the decline of aristocratic southern Compsons family.

Narrative transposition of characters is motivated by the modality of tragic, where the narration begins on behalf of mentally handicapped Benjy, who on this day reaches the age of 33 years. The narrator of this chapter is not capable of any assessment or characterization of either the characters that surround him or the events in which he participates. In essence, the author creates such a chaos of Benjy's irrational impressions on an empirical level that it is very difficult to orientate in the text and logically put together the story of "idiot" Benjy through his discourse of 
"stream of consciousness". Thus, W. Faulkner forms a very fragmented and vague idea of the history of the Compson family in "faces." Prerequisites for the emergence of a complex chapter II is a primitive by Benjy. In the second chapter of the novel "June 2, 1910", art reality is presented by William Faulkner from the point of view of an intellectual-philosopher, the discourse of the "stream of consciousness" of which is absolutely opposite to the narrative on behalf of Benjy. B. Gribanov notes the following: “when moving from Benjy's part to Quentin's part, a dramatic qualitative leap occurs in the manner of narration - from the disjointed thoughts of an idiot whose brain can only fix what is happening, but not why, to the complex associative thinking of an intellectual whose brain easily passes from one thought to another, where ideas, allusions, memories, abstractions, symbols are mixed. "(Gribanov, 1976 ). The main character and narrator of Chapter III (April 6, 1928) is the practical, pragmatic and very cynical younger brother of the Compson family, Jason, whose main purpose of life is hoarding and money. This type of narrative transposition of characters makes it possible to create a figurative antithesis, where the past personifies all that is good and the present is exactly the opposite. The narrative of chapter IV is organized by the objective focus of the author himself. Accordingly, W. Faulkner achieves the effect of "crescendo" in tonality, a kind of "clarity" or "lucidity".

Thus, all narrative transpositions are not W. Falkner's an end in itself. It seems that this technique does not provoke a complex perception of the novel, it is logically motivated by the author's main idea and psychological, intellectual and social features of each narrator.

\section{References:-}

1. Andreeva K.A., (2008). Cognitive modeling of mental literary space (from author to the reader). Word, statement, text in cognitive, pragmatic and culturological aspects. V 1. Chelyabinsk, pp. 7-11.

2. Belousova E.A. (2012). Speech portrait as the implementation of a descriptive model at the macro-level of literary text. Bulletin of the Moscow State Linguistic University. - Issue 14 (647), pp. 9-16.

3. Dolinin A.(1985) - Faulkner W. Complete works.; M .: Fiction, V, 1.- pp. 331-590.

4. Dedova O.V.( 2001). The linguistic concept of hypertext: basic concepts and terminological paradigm. Vestnik MGU. Ser. 9, Philology . №4, pp. 22-36.

5. Farino E. (2004). Introduction to Literary Study: Textbook. SPb.: Publishing RGPU them. A.I. Herzen, pp. 363364.

6. Gribanov B.T. (1976). Faulkner. M .: Young Guard, pp. 117.

7. Koltsova, L.M., Lunina, O.A. (2007). Literary text in the modern linguistic paradigm: Training manual for universities. Voronezh, pp. 5.

8. Matveyeva N. I. ( 2003), "The narrative structure of the English-speaking literary discourse: On the material of the" stream of consciousness " novels of the beginning of the 20th century." (Thesis.) [Electronic resource] .Access mode:http://www.dissercat.com/content/narrativnaya-struktura-angloyazychnogo-khudozhestvennogodiskursa-na-materiale-romanov-poto

9. Schmid V. M. (2003). Narratology. Languages of Slavic culture, pp. 145

10. Todorov T. (1966). Les categories du recit litteraire//Communications. № 8, pp. 125-151.

11. Turaeva Z.Ya. (1986). Text linguistics: (Text: structure and semantics). - M.: Enlightenment, pp. $13 ; 210$.

12. Ushnikova E. A., Ushnikova O. V. (2010). Peculiarities of time category functioning in the narrative // Herald of ChSU. № 4 (61), Philological Sciences, pp. 59-63. 